\title{
Current Challenges in the Diagnosis and Management of Selective Mutism in Children
}

This article was published in the following Dove Press journal:

Psychology Research and Behavior Management

\author{
Peter Muris iD ${ }^{1,2}$ \\ Thomas H Ollendick ${ }^{3,4}$ \\ 'Department of Clinical Psychological \\ Sciences, Faculty of Psychology and \\ Neuroscience, Maastricht University, \\ Maastricht, the Netherlands; \\ ${ }^{2}$ Departement Sielkunde, Stellenbosch \\ University, Stellenbosch, South Africa; \\ ${ }^{3}$ Department of Psychology, Virginia \\ Polytechnic Institute and State University, \\ Blacksburg, VA, USA; ${ }^{4}$ Department of \\ Psychology, University of Roehampton \\ London, London, UK
}

\begin{abstract}
Selective mutism (SM) is a childhood disorder characterized by a consistent failure to speak in specific social situations (eg, school) despite speaking normally in other settings (eg, at home). This article summarizes evidence supporting the recent classification of SM as an anxiety disorder and discusses the implications of this re-classification for the assessment and treatment of SM in clinical practice. Meanwhile, clinicians should also realize that SM sometimes is a heterogeneous disorder in which other problems are also present that complicate the management of children with SM. As examples, we discuss speech and language problems, developmental delay, and autism spectrum disorders.
\end{abstract}

Keywords: selective mutism, anxiety disorder, assessment, treatment

\section{Introduction}

Selective mutism (SM) is a psychological condition usually occurring during childhood that is characterized by a total absence of speech in specific social situations while speech production appears to be normal in other situations. For example, children with SM may not respond to a question posed by the teacher in class and/ or do not speak to peers at school, but do verbally communicate with parents, siblings, or other familiar people encountered in the home environment. To formally establish the diagnosis, current classification systems presume that the selective non-speaking behavior is required to be present for at least 1 month, should not be attributable to a lack of knowledge of, or discomfort with, the spoken language required in the social situation, and has to interfere significantly with daily functioning in school, work, or social life. Furthermore, the disturbance is not better explained by a communication disorder (eg, childhood-onset fluency disorder) and does not occur exclusively during the course of autism spectrum disorder, schizophrenia, or another psychotic disorder. ${ }^{1,2}$

$\mathrm{SM}$ is a relatively rare disorder. Estimates on its point prevalence have been obtained in clinic or school samples in various countries and typically range between $0.03 \%$ and $1.9 \%$ depending on the setting (eg, clinic vs school/general population) and ages of the children in the sample. ${ }^{3} \mathrm{SM}$ is typically an earlyonset condition, starting usually before the age of 5 years and often becoming a focus of clinical attention when children enter school. ${ }^{1}$ The course of SM is variable: some children continue to demonstrate the prototypical muteness associated with the disorder, but in many young people the selective nonspeaking behavior gradually diminishes while symptoms of social reticence and social anxiety often remain. ${ }^{4,5}$
Department of Clinical Psychological Sciences, Faculty of Psychology and Neuroscience, Maastricht University, P.O. Box 616, Maastricht, 6200 MD, The Netherlands

Email peter.muris@maastrichtuniversity.nl 
The dramatic symptomatology of SM has puzzled researchers and clinicians in both psychology and psychiatry for almost one and a half centuries. Initially, SM was conceptualized as an oppositional behavior problem - as evidenced by previously employed labels such as "voluntary aphasia" and "elective mutism" suggesting that these children intentionally choose to remain mute in certain situations or with certain people. The current view is more neutral regarding children's motives, with the term "selective" referring to the fact that children's lack of speech only occurs in particular contexts or settings. ${ }^{1,8}$ Moreover, the generally accepted idea is that the prototypical non-speaking behavior of children with this disorder is fueled by fear and apprehension that predominantly occurs in certain social situations, which is why SM is now regarded as an anxiety pathology.

In this article, we will first summarize research evidence supporting that there indeed is an intimate link between SM and (social) anxiety that justifies its recent reclassification as an anxiety disorder. We will then discuss the implications of viewing SM as an anxiety disorder for the classification, assessment, and treatment of this condition. Next, we will point out that - although we agree that anxiety is clearly implicated, there are also indications that $\mathrm{SM}$ is a heterogeneous disorder in which a number of other psychopathological and developmental phenomena are possibly involved. We argue that this related phenomenology should not be neglected in the assessment and clinical management of children with this debilitating disorder.

\section{Empirical Evidence on the Link Between SM and (Social) Anxiety}

Evidence for the relation between SM and (social) anxiety essentially comes from three lines of research. The first research line is concerned with the investigation of the comorbidity rates between SM and anxiety pathology. A recently published meta-analysis nicely summarizes the results of 22 studies in which clinical interviews were conducted in children with SM to establish the co-occurrence of other anxiety disorders. ${ }^{9}$ The results showed that $80 \%$ of the children with SM also fulfilled the diagnostic criteria for at least one other anxiety disorder, and in the vast majority of cases $(69 \%)$ this involved social anxiety disorder (SAD). A second line of inquiry has focused on the content of the fears and fear-related cognitions of children with SM. For example, Vogel et al interviewed children with SM about their fears and worries in speech-related situations and assessed their levels of social fear-related cognitions in comparison to typically developing children and children with SAD. ${ }^{10}$ The qualitative interviews revealed that the content of the fears reported by children with SM were predominantly focused on typical social anxiety themes (ie, fear of being scrutinized and being critically or negatively evaluated by other people). The quantitative comparisons revealed that children with SM reported equally high levels of negative fear-related cognitions as children with SAD, with both clinical groups displaying higher scores than typically developing children. A third and final line of research has to do with the temperament characteristics of children with SM. There is increasing evidence that children with SM display high levels of shyness, become easily distressed when facing novelty, and have a tendency to withdraw from unfamiliar situations. ${ }^{11-13}$ These are all defining features of the temperament typology of "behavioral inhibition to the unfamiliar" ${ }^{\prime 4}$ which has been demonstrated as an important vulnerability factor of anxiety pathology, and SAD in particular. ${ }^{15,16}$

Taken together, it can be concluded that there is a clear link between SM and fear and anxiety, which justifies the decision of current classification systems to categorize SM as an anxiety disorder. ${ }^{1,2,17}$ Further, SM appears to have a special relation with social anxiety, which has prompted some scholars to argue that SM should be regarded as a variant of, and more in specific a developmental precursor of SAD ${ }^{18}$ which seems to be supported by its early age-ofonset in combination with the observation that full muteness usually disappears when children become older. ${ }^{4,5}$ This link has been confirmed by empirical studies which have noted that there are clear similarities between children with SM and children with SAD in terms of fear content and levels of fear and anxiety. ${ }^{10,19-22}$ The main implication of this observation for clinicians is that when they encounter a child with SM they should at least initially manage the case as any other anxiety disorder. ${ }^{3,17}$ Of course, if co-occurring disorders also are present they too will need to become part of the clinical management picture. What that implies will be the topic of our next section.

\section{Clinical Management of SM as an Anxiety Disorder Classification and Assessment}

Clinicians can employ the SM module of the Anxiety Disorders Interview Schedule for Children and Parents 
$(\text { ADIS-C/P })^{23}$ or the Schedule for Affective Disorders and Schizophrenia for Children (Kiddie- or K-SADS) ${ }^{24}$ to formally establish the diagnosis of the disorder. Other modules of these instruments can also be used to check frequent comorbid conditions, notably $\mathrm{SAD}$ and other anxiety problems. Normally, these semi-structured clinical interviews are administered to both the child and the parent. However, given the key symptom of the condition (ie, the non-speaking behavior), it is likely that one will need to rely only on the parent as the primary informant.

To get an impression of the severity of the problem and to eventually monitor treatment progress, the Selective Mutism Questionnaire (SMQ) ${ }^{25}$ can be administered. This parent-based scale consists of 17 items measuring the frequency of children's non-speaking behavior across various settings, ie, at home, in school, and in other public/social situations. The SMQ is a reliable scale and there is also evidence for its validity. ${ }^{25-27} \mathrm{~A}$ recently developed alternative instrument is the Frankfurt Scale of Selective Mutism (FSSM). ${ }^{28}$ The FSSM is a parent-report measure that not only yields a severity index of SM symptoms but also includes a diagnostic scale that can be used to evaluate the presence of the core characteristics of the disorder and hence serves to support the establishment of the diagnosis.

Oftentimes, the lack of speech in school is the most important reason for parents to seek help for their child, and so an assessment of SM symptoms in the school situation is particularly relevant. For this purpose, an observation is indicated to actually witness the muteness in class and during other school activities. When this is not feasible, the School Speech Questionnaire (SSQ) ${ }^{29}$ can be a useful tool to measure the teacher's perception of the frequency of children's non-speaking behavior.

In spite of the fact that SM now belongs to the category of anxiety disorders, it is remarkable that its defining criteria do not explicitly refer to fear and anxiety. This means that clinicians need to employ other assessment instruments to obtain information on this important aspect of the problem. Given the young age of many children with SM, parent-report questionnaires are the main source of information, ${ }^{30}$ but as children become older it is also possible to employ self-report scales to assess the intensity and frequency of fear and anxiety symptoms, in particular in the social domain. The Social Anxiety Scale for Children $^{31}$ and the Social Phobia and Anxiety Inventory ${ }^{32}$ are excellent choices for this purpose.

\section{Treatment}

With the acknowledgement that SM primarily is a fearand anxiety-driven problem, it is good to see that - at least in the scientific literature - cognitive-behavioral therapy (CBT) is generally recognized as the most feasible intervention for children with this disorder. Briefly, CBT for SM consists of the same components that also constitute CBT for other anxiety disorders, ${ }^{33}$ namely (1) psychoeducation - defining SM as an expression of anxiety and specifically of social anxiety; (2) physiological training breathing and muscle relaxation; (3) behavioral training contingency management, hierarchical exposure, modeling, shaping, and gradual desensitization; (4) cognitive training - positive self-talk and cognitive restructuring; and (5) parent training - enhancing parents' skills in assisting their child and gradually discontinuing the mutism behaviors. ${ }^{34}$

Figure 1 provides an overview of the psychosocial approaches that were investigated as treatments for children with SM in studies conducted in the time periods 1980-1996, 1995-2005, and 2005-2015. ${ }^{35-37}$ It can be seen that ever since 1980, CBT interventions for SM have always been the most popular in research settings; moreover, during the final decade almost no intervention study can be found that did not include strategies such as reinforcement, exposure, and cognitive restructuring. It is also clear that researchers have focused less on the psychodynamic treatment of SM but have gained increasing interest in the systems approach (see Figure 1).

The research on the outcome of interventions for children with SM is still somewhat inconclusive. This is because many studies have only described the effects of treatment in a single case or just a few children with SM, which of course hinders the generalization to other youngsters suffering from the condition. Meanwhile, three controlled trials have been published and all have evaluated the efficacy of CBT on the non-speaking behavior and associated anxiety symptomatology of children with SM. In the first investigation, Bergman et al evaluated a 20 session CBT-based program that mainly consisted of behavioral techniques. ${ }^{38}$ Twenty-one children with SM were randomly assigned to CBT or a waitlist control condition. It was found that $67 \%$ of the children who had received CBT no longer fulfilled the diagnostic criteria of SM, whereas $0 \%$ of the children in the waitlist condition attained such a diagnosis-free status. Moreover, on standardized measures completed by parents and teachers, the 


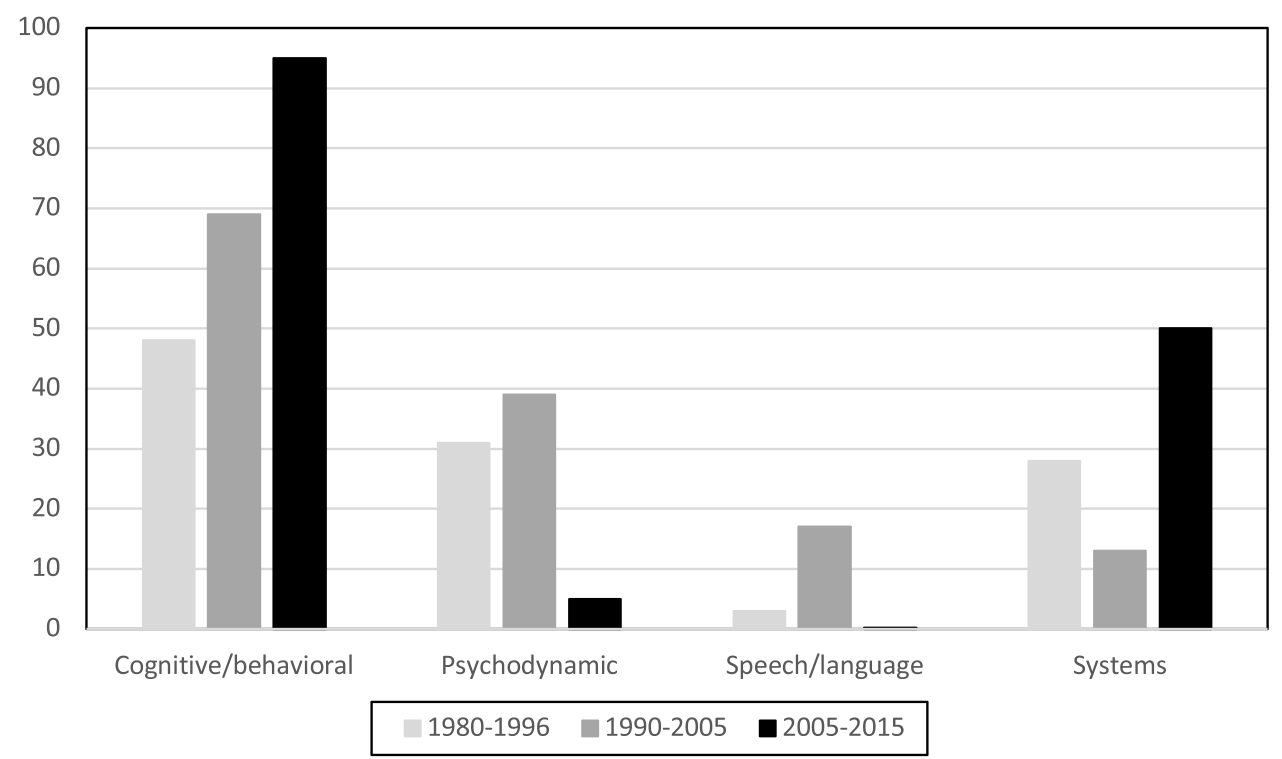

Figure I Overview of research on psychosocial interventions for children with SM. For each period, the percentages of studies incorporating various treatment modalities are shown.

Note: Data from these studies. ${ }^{35-37}$

children treated with CBT were reported to display increased functional speaking and decreased levels of social anxiety, which were positive developments that did not occur in children in the waitlist condition. Similar findings were obtained in two other controlled investigations by Cornacchio et $\mathrm{al}^{39}$ and Oerbeck et $\mathrm{al}^{40}$ that also compared the effects of a CBT for children with SM versus a waitlist control condition. Children of the latter study were re-assessed 5 years after termination of treatment, ${ }^{41}$ and the results revealed that $70 \%$ were no longer diagnosed with SM at this long-term follow-up, whereas a further $17 \%$ of the children were in partial remission. Meanwhile, $23 \%$ of children met the criteria for $\mathrm{SAD}$, and $50 \%$ found it challenging to talk outside of home. This indicates that although the positive effects of the intervention were largely maintained, a substantial number of the children showed persistent problems, which of course highlights the need for developing even more effective treatments.

For other childhood anxiety disorders, pharmacotherapy, and in particular treatment with selective serotonin reuptake inhibitors (SSRIs), is considered a viable intervention option. ${ }^{42}$ The general clinical guideline is that SSRIs are indicated when CBT yields an insufficient treatment response, ${ }^{43}$ but there are also indications that a combination of CBT and pharmacotherapy may be even more effective in treating anxiety disorders in children and adolescents than each of both monotherapies on their own. ${ }^{44}$ Research on the efficacy of SSRIs in children with SM is sparse, which is not that surprising given the possible side effects of this type of medication $^{42}$ and the fairly young age of most children with this condition. ${ }^{3}$ The few studies that have been conducted are limited by small numbers, heterogeneous designs, the absence of a comparison group, and lack of consistent outcome measures. Nonetheless, the results suggest that SSRIs yield symptomatic improvement, although it remains largely unclear how many children achieve full remission. ${ }^{45}$ So far, support for a combination treatment of CBT and SSRI in the treatment of SM is missing. ${ }^{46}$

There are indications that outcome is better when children with SM are treated at a younger age. ${ }^{41}$ This also raises the question of whether it is possible to implement early interventions thereby averting the development of the persistent pattern of non-speaking behavior associated with the disorder. Given the strong relationship between SM and behavioral inhibition, this temperament trait might be an important target for such a preventive approach. The trait is easily detectable and can be effectively addressed by means of a brief parent-based intervention program that aims to promote exposure, adjust negative thinking, and enhance social skills. ${ }^{47}$ In a series of studies, it has been demonstrated that this intervention delivered to inhibited preschool children can reduce the development of childhood anxiety disorders both on the short- and the long-term, ${ }^{48-52}$ and it 
would be interesting to study whether this approach is also useful of altering the trajectory of SM.

Taken together, anxiety is a prominent symptom of children with SM and as such the most logical approach is to treat the condition not unlike that of any other anxiety disorder. CBT-based interventions are certainly the number one option for treating SM, and it is good to see that this notion has increasingly percolated into ongoing research. ${ }^{37}$ This does not automatically imply that this is also true for clinical practice. Kazdin ${ }^{53}$ rightly noted that there still exists a huge gap between assessments and treatments that have been demonstrated as "evidence-based" and what is actually used by clinicians in their daily practice. For instance, many clinicians still rely on psychodynamicbased interventions such as play therapy when dealing with children with SM. It is not our intention to downplay the importance of play therapy - especially when working with young children this is certainly a valuable method, but given the extant empirical evidence, it is strongly recommended to incorporate CBT elements within such an intervention. ${ }^{54}$

Another example is concerned with commonly encountered advice on how therapists should approach a child with SM. For instance, on the basis of their clinical expertise, Oerbeck et $\mathrm{al}^{40}$ have advanced the principle of "defocused communication", which requires the therapist

to sit beside rather than opposite the child, to conduct a joint activity ..., to think aloud rather than asking the child direct questions, to give the child enough time to respond ..., and try to receive a verbal answer in a neutral way. (p. 195)

Unfortunately, there is no empirical evidence for the unique effect of defocused communication in the treatment of children with SM. Further, although it seems a good strategy to "break the ice" during the initial stage of therapy, the technique seems less appropriate when treatment progresses to a point that exposure exercises have to be conducted during which the child is required to speak and to respond to questions in real-life situations.

\section{SM: More Than an Anxiety Disorder?}

Although the role of fear and anxiety is prominent in SM, it is good to be aware that there is considerable evidence indicating that other psychopathologies or difficulties may fuel children's apprehension for speaking in social situations. In this section, we will discuss a number of such problems and also address implications for the clinical management of children with SM.

\section{Speech and Language Problems and Developmental Delay}

One case in point are speech and language problems, which have been shown to be present in a considerable proportion of children with SM. For example, Steinhausen and $\mathrm{Juzi}^{55}$ examined the clinical characteristics of 100 children with SM. It was found that $38 \%$ of the children with SM also displayed early speech and language disorders. In particular, articulation disorder $(20 \%)$ and expressive language disorder (28\%) were highly prevalent. In another study, ${ }^{56} 54$ children with SM and 108 control children were subjected to a comprehensive assessment while their parents were interviewed by means of a diagnostic interview. The results showed that children with SM were more often characterized by a developmental delay - and this was often concerned with language problems (51.9\%), as compared to children in the control group (11.1\%). In terms of comorbid diagnoses, the DSM-IV classifications of phonological disorder (42.6\%), mixed receptive-expressive language disorder (17.3\%), and expressive language disorder (11.5\%) were clearly more prevalent among the children with SM (percentages in the control group being $10.2 \%, 1.0 \%$, and $1.0 \%$, respectively). In further research, Manassis and colleagues $^{57}$ employed standardized language tests to explore whether children with SM differed from (socially) anxious and normal control children with regard to their language skills and abilities. It was found that children with SM relative to children in the other groups consistently displayed a poorer performance on linguistic tasks, although it was also noted that this not always implied that they all suffered from speech and language disorders. A final investigation by Cohan et $\mathrm{al}^{58}$ adopted a quantitative approach in which parent-based measures were used to assess social anxiety, behavioral problems, and language delays in 130 children with SM. Subtypes of SM were identified by means of a cluster analysis. The results revealed that besides subtypes of exclusively anxious children and anxious-mildly oppositional children, evidence was found for a third subgroup of children with SM showing a mix of anxiety and (sub)clinical levels speech and syntax problems.

Collectively these findings indicate that there is a subset of children with SM who display delayed and 
impaired speech and language skills. It is easy to see how these difficulties prompt children to become apprehensive of school and other social situations in which they are required to speak, and this may be particularly true for those who also have a (genetic/temperamental) susceptibility for anxiety. Two obvious clinical implications follow from the observation that speech and language problems are present in some children with SM. The first one is that it would be good practice to conduct a proper clinical assessment in order to get a picture of a child's general developmental level, which also includes a careful evaluation of speech, receptive language, expressive language, and phonology. ${ }^{59}$ Receptive language tests such as the Peabody Picture Vocabulary Test ${ }^{60}$ can be administered in a non-verbal way, but the evaluation of other aspects of language and speech require the child to speak. To deal with this problem, the clinician could ask parents to make an audiotape recording of the child speaking in the home situation, or train parents to administer the standardized test materials, a method that has been proven to yield reliable and valid information about children's level of speech and language. ${ }^{61}$ The second implication only applies if the assessment indeed reveals the presence of speech and language problems in a child with SM. In that case, a speech therapist should be involved to remediate the speech and language difficulties and bolster the confidence of the child in its speech and linguistic abilities. ${ }^{59}$

\section{Autism Spectrum Problems}

Although the presence of autism spectrum disorder (ASD) is considered as an exclusion criterion of SM, the more dimensional approach of psychopathology taken by the current DSM- $5^{1}$ makes it difficult for clinicians to establish a clear boundary between these two conditions. Meanwhile, there is increasing research evidence showing that there is a clear relation between SM and ASD. For example, Steffenburg et $\mathrm{al}^{62}$ conducted a detailed analysis of the medical records of 97 children who had been referred to the clinic with SM as the primary diagnosis. The post hoc analysis revealed that $62 \%$ of the children with SM could also be diagnosed with ASD: in DSM-IV terms: $29 \%$ had autistic disorder, $4 \%$ had Asperger's syndrome, and $29 \%$ had pervasive developmental disorder-not otherwise specified. Further, an additional $20 \%$ of children clearly showed autistic features but did not receive a formal ASD diagnosis, which means that in this sample only $18 \%$ showed no overt signs of ASD. In another study by Klein et $\mathrm{al}^{63}$ that included 42 clinically referred children with SM, parents and teachers completed the Behavior Assessment System for Children (BASC), ${ }^{64}$ a standardized scale for measuring internalizing symptoms, externalizing problems, and adaptive skills. Interestingly, the BASC also contains a clinical index that consists of specific items relating to developmental social problems, atypicality, and withdrawal that would be indicative of the presence of ASD. Findings indicated that $80 \%$ of the children with SM scored above the cut-off of this autism probability index, with many of the children showing signs of social and communication problems and stereotyped interests and behaviors. A further investigation by Nowakowski et $\mathrm{al}^{65}$ had the purpose to analyze the interactions of children with SM and their parents by focusing on joint attention abilities. Joint attention is defined as the shared focus of two individuals on an object or event that is achieved when one individual alerts the other person by means eye-gazing, pointing, and verbal directions. Importantly, this ability has been shown to be impaired in children with ASD. In the Nowakowski et al study, joint attention abilities of children with SM, children with other anxiety problems, and control children were assessed under two conditions: during unstructured free play and during a number of structured tasks (eg, the parent had to prepare the child for a speech in front of the camera). No differences were found between the three groups with regard to the level of joint attention behaviors during the unstructured free play condition. However, under more structured conditions, children with SM appeared to establish significantly fewer joint attention episodes following parental initiation as compared to children and parents in the other two groups, which tentatively indicates that children with SM (to some extent) display a cognitive deficit that has also been observed in children with ASD. A final study by Stein et $\mathrm{al}^{66}$ adopted a pathophysiological approach to study the link between SM and ASD. In 99 families that included 106 children with SM, a number of single nucleotide polymorphisms (SNPs) in the contactin-associated protein-like 2 (CNTNAP2) were genotyped. The results showed that the SNP $r s 2710102$ was significantly associated with the presence of SM. Because the CNTNAP2 is known as a susceptibility gene for ASD, Stein et al concluded that some forms of SM share a similar genetic liability with disorders in the autism spectrum.

Although studies on the link between SM and autism spectrum problems are subject to various methodological 
shortcomings,${ }^{67}$ findings indicate that some children with SM do show clear signs or even meet full criteria of this neurodevelopmental disorder. In a recent review, ${ }^{67}$ we have advocated to revise the current classification criteria of SM and to allow SM and ASD to be comorbid conditions, just as is currently done with SAD and ASD. The observation that ASD is present in some children with SM has a number of clinical implications. To begin with, it is critical to assess symptoms of ASD during the diagnostic evaluation of children who do not speak in specific social situations. To conduct such assessment in an effective and economic way, a two-step procedure as described by Volkmar et $\mathrm{al}^{68}$ could be adopted. This procedure consists of a first screening of ASD symptoms by means of a scale that has been specifically developed for this purpose (eg, the Social Communication Questionnaire), ${ }^{69}$ followed by a more extensive diagnostic evaluation by means of the Autism Diagnostic Observation Scale (ADOS) ${ }^{70}$ and the Autism Diagnostic Interview (ADI), ${ }^{71}$ which are currently considered the gold standard assessment instruments for establishing ASD. The use of more objective measures such as the ADOS and ADI is not only helpful to establish the presence of autistic features in children with SM but could also identify children who only have SM and who are currently - by some clinicians - erroneously labelled as cases of ASD.

The presence of ASD will also have repercussions for the treatment of SM. The delivery of the regular CBT intervention needs to be optimized by increasing the use of visual aids, providing more structure, incorporating extra sessions, and adding more relaxation exercises. ${ }^{72}$ Furthermore, it may be necessary to add special treatment components that target specific social problems that occur in children with this neurodevelopmental disorder. For example, Pallathra et $\mathrm{al}^{73}$ noted that individuals with ASD show specific impairments in social cognition, social skills, and social motivation, all of which require attention during treatment. Moreover, the often inflexible and rigid behavior of children with ASD may also require clinical attention, either by specific behavioral interventions or by prescribing antipsychotic medication.

\section{Conclusion}

$\mathrm{SM}$ is a rare but debilitating disorder that has puzzled researchers and clinicians for a long time. Empirical insights indicate that SM is mainly fear- and anxiety-driven and as such clinicians need to approach the condition as an anxiety disorder. ${ }^{3,17}$ In a nutshell this implies that the assessment procedure besides an index of speaking frequency should incorporate (social) fear and anxiety scales, while treatment has to be CBT-based as this currently is the best available empirically-supported intervention for childhood anxiety disorders. Meanwhile, the cautionary note has to be made that this may not be the full story. As pointed out by various authors, ${ }^{74,75} \mathrm{SM}$ is likely to be a heterogeneous disorder. This means that while in some children fear and anxiety may be the sole basis of nonspeaking behavior in specific social situations, there are other children for whom other psychopathologies and difficulties contribute to the etiology and expression of SM. In this brief article, we have discussed the examples of speech and language problems, developmental delay, and autism spectrum disorder in the hope that clinicians will address these factors in their assessment, and ultimately deploy the most optimal treatments in children with SM.

\section{Disclosure}

The authors report no conflicts of interest in this work.

\section{References}

1. American Psychiatric Association. Diagnostic and Statistical Manual of Mental Disorders. fifth ed. Burlington, VA: American Psychiatric Association; 2013.

2. World Health Organization. International classification of diseases for mortality and morbidity statistics (11th revision); 2018. Retrieved from https://icd.who.int. Accessed February 4, 2021.

3. Viana AG, Beidel DC, Rabian B. Selective mutism: a review and integration of the last 15 years. Clin Psychol Rev. 2009;29(1):57-67. doi:10.1016/j.cpr.2008.09.009

4. Remschmidt H, Poller M, Herpertz-Dahlmann B, Hennighausen K, Gutenbrunner C. A follow-up study of 45 patients with elective mutism. Eur Arch Psychiatry Clin Neurosci. 2001;251:284-296.

5. Steinhausen HC, Wachter M, Laimböck K, Winkler Metzke C. A long-term outcome study of selective mutism in childhood. $J$ Child Psychol Psychiatry. 2006;47:751-756.

6. Kussmaul A. Die Störungen Der Sprache (The Disturbances of Speech). Basel, Switzerland: Benno Schwabe; 1877.

7. Tramer M. Elektiver Mutismus bei Kindern (Elective mutism in children). Z Kinderpsychiatr. 1934;1:30-35.

8. American Psychiatric Association. Diagnostic and Statistical Manual of Mental Disorders. fourth ed. Washington, DC: American Psychiatric Association; 1994.

9. Driessen J, Blom JD, Muris P, Blashfield RK, Molendijk M. Anxiety in children with selective mutism: a meta-analysis. Child Psychiatry Hum Dev. 2020;51:330-341.

10. Vogel F, Gensthaler A, Stahl J, Schwenck C. Fears and fear-related cognitions in children with selective mutism. Eur Child Adolesc Psychiatry. 2019;28(9):1169-1181. doi:10.1007/s00787-019-01281-0

11. Genthaler A, Khalaf S, Ligges M, Kaess M, Freitag CM, Schwenck C. Selective mutism and temperament: the silence and behavioral inhibition to the unfamiliar. Eur Child Adolesc Psychiatry. 2016;25:1113-1120. doi:10.1007/s00787-016-0835-4

12. Milic MI, Carl T, Rapee RM. Similarities and differences between young children with selective mutism and social anxiety disorder. Behav Res Ther. 2020;133:103696. doi:10.1016/j. brat.2020.103696 
13. Muris P, Hendriks E, Bot S. Children of few words: relations among selective mutism, behavioral inhibition, and (social) anxiety symptoms in 3- to 6-year-olds. Child Psychiatry Hum Dev. 2016;47 (1):94-101. doi:10.1007/s10578-015-0547-x

14. Kagan J. Galen's Prophecy: Temperament in Human Nature. New York: Routledge; 1994.

15. Clauss JA, Blackford JU. Behavioral inhibition and the risk for developing social anxiety disorder: a meta-analytic study. $J \mathrm{Am}$ Acad Child Adolesc Psychiatry. 2012;51:1066-1075. doi:10.1016/j. jaac.2012.08.002

16. Ollendick TH, Benoit K. A parent-child interactional model of social anxiety disorder in youth. Clin Child Fam Psychol Rev. 2012;15:81-91. doi:10.1007/s10567-011-0108-1

17. Sharp WG, Sherman C, Gross AM. Selective mutism and anxiety: a review of the current conceptualization of the disorder. J Anx Disord. 2007;21(4):568-579. doi:10.1016/j.janxdis.2006.07.002

18. Bögels SM, Alden L, Beidel DC, et al. Social anxiety disorder: questions and answers for DSM-V. Depress Anxiety. 2010;27:168-189. doi:10.1002/da.20670

19. Gensthaler A, Maichrowitz V, Kaess M, Ligges M, Freitag CM, Schwenck C. Selective mutism: the fraternal twin of childhood social phobia. Psychopathology. 2016;49(2):95-107. doi:10.1159/ 000444882

20. Manassis K, Fung D, Tannock R, Sloman L, Fiksenbaum L, McInnes A. Characterizing selective mutism: is it more than social anxiety? Depress Anxiety. 2003;18(3):153-161. doi:10.1002/ da. 10125

21. Poole KL, Cunningham CE, McHolm AE, Schmidt LA. Distinguishing selective mutism and social anxiety in children: a multi-method study. Eur Child Adolesc Psychiatry. 2020. doi:10.1007/s00787-020-01588-3

22. Yeganeh R, Beidel DC, Turner SM. Selective mutism: more than social anxiety? Depress Anxiety. 2006;23(3):117-123. doi:10.1002/ da.20139

23. Albano AM, Silverman WK. Anxiety Disorders Interview Schedule for Children and Parents, DSM-IV Version. New York: Graywind; 1996.

24. Kaufman J, Birmaher B, Axelson D, Pereplitchikova F, Brent D, Ryan N. The K-SADS-PL DSM-5. Baltimore, MD: Kennedy Krieger Institute; 2016.

25. Bergman RL, Keller ML, Piacentini J, Bergman AJ. The development and psychometric properties of the Selective Mutism Questionnaire. J Clin Child Adolesc Psychol. 2019;28(2):456-464. doi:10.1080/15374410801955805

26. Letamendi AM, Chavira DA, Hitchcock CA, Roesch SC, ShiponBlum E, Stein MB. Selective Mutism Questionnaire: measurement structure and validity. J Am Acad Child Adolesc Psychiatry. 2008;47 (10):1197-1204. doi:10.1097/CHI.0b013e3181825a7b

27. Oerbeck B, Overgaard KR, Bergman RL, Pripp AH, Kristensen H. The Selective Mutism Questionnaire: data from typically developing children and children with selective mutism. Clinical Child Psychology and Psychiatry. 2020;25(4):754-765. doi:10.1177/ 1359104520914695

28. Gensthaler A, Dieter J, Raisig S, et al. Evaluation of a novel parent-rated scale for selective mutism. Assessment. 2020;27 (5):1007-1015. doi:10.1177/1073191118787328

29. Bergman RL, Piacentini J, McCracken JT. Prevalence and description of selective mutism in a school-based sample. J Am Acad Child Adolesc Psychiatry. 2002;41(8):938-946. doi:10.1097/00004583200208000-00012

30. Spence SH. Assessment of fear and anxiety in preschool children: parent and teacher report. In: Fisak B, Barrett P, editors. Anxiety in Preschool Children: Assessment, Treatment, and Prevention. New York: Routledge; 2019.
31. LaGreca AM, Stone WL. Social Anxiety Scale for Children-Revised: factor structure and concurrent validity. J Clin Child Psychol. 2016;49(1):17-27. doi:10.1207/s15374424jccp2201_2

32. Beidel DC, Turner SM, Morris TL. A new inventory to assess childhood social anxiety and phobia: the Social Phobia and Anxiety Inventory for Children. Psychol Asses. 1995;7(1):73-79. doi:10.1037/1040-3590.7.1.73

33. Kendall PC. Treating anxiety disorders in children: results of a randomized clinical trial. J Consult Clin Psychol. 1994;62 (1):100-110. doi:10.1037/0022-006X.62.1.100

34. Lang C, Nir Z, Gothelf A, et al. The outcome of children with selective mutism following cognitive behavioral intervention: a follow-up. Eur J Pediatr. 2016;175:481-487.

35. Anstendig K. Selective mutism: a review of the treatment literature by modality from 1980-1996. Psychother. 1998;35:381-391.

36. Cohan SL, Chavira SL, Stein MB. Practitioner review: psychosocial interventions for children with selective mutism: a critical evaluation of the literature from 1990-2005. J Child Psychol Psychiatry. 2006;47:1085-1097.

37. Zakszeski BN, DuPaul GJ. Reinforce, shape, expose, and fade: a review of treatments for selective mutism (2005-2015). School Ment Health. 2017;9:1-15.

38. Bergman RL, Gonzales A, Piacentini J, Keller ML. Integrated behavior therapy for children with selective mutism. Behav Res Ther. 2013;51:680-689.

39. Cornacchio D, Furr JM, Sanchez AL, et al. Intensive group behavioral treatment for children with selective mutism: a preliminary randomized clinical trial. J Consult Clin Psychol. 2019;87:720-733.

40. Oerbeck B, Stein MB, Wentzel-Larsen T, Langsrud O, Kristensen H. A randomized controlled trial of a home and school-based intervention for selective mutism: defocused communication and behavioural techniques. Child Adolesc Mental Health. 2014;19:192-198.

41. Oerbeck B, Overgaard KR, Stein MB, Pripp AH, Kristensen H. Treatment of selective mutism: a 5-year follow-up. Eur Child Adolesc Psychiatry. 2018;27:997-1009.

42. Ollendick TH, March JS. Phobic and Anxiety Disorders in Children and Adolescents: A Clinician's Guide to Effective Psychosocial and Pharmacological Interventions. New York: Oxford University Press; 2004.

43. Muris P. Treatment of childhood anxiety disorders: what is the place for antidepressants? Expert Opin Pharmacother. 2012;13:43-64.

44. Walkup JT, Albano AM, Piacentini J, et al. Cognitive behavioral therapy, sertraline, or a combination in childhood anxiety. New Engl J Med. 2008;359:2753-2766.

45. Manassis K, Oerbeck B, Overgaard KR. The use of medication in selective mutism: a systematic review. Eur Child Adolesc Psychiatry. 2016;25:571-578.

46. Ostergaard KR. Treatment of selective mutism based on cognitive behavioral therapy, psychopharmacology, and combination therapy: a systematic review. Nord J Psychiatry. 2018;72:240-250.

47. Rapee RM. The development and modification of temperamental risk for anxiety disorders: prevention of a lifetime of anxiety? Biol Psychiatry. 2002;52:947-957.

48. Hirshfeld-Becker DR, Masek B, Henin A, et al. Cognitive behavioral therapy for 4-7-year-old children with anxiety disorders: a randomized clinical trial. J Consult Clin Psychol. 2010;78:498-510.

49. Rapee RM, Edwards SL. A selective intervention program for inhibited preschool-aged children of parents with an anxiety disorder: effects on current anxiety disorders and temperament. J Am Acad Child Adolesc Psychiatry. 2009;48:602-609.

50. Rapee RM, Edwards SL. Altering the trajectory of anxiety in at risk young children. Am J Psychiatry. 2010;167:1518-1525.

51. Rapee RM, Kennedy S, Ingram M, Edwards S, Prevention SL. Early Intervention of Anxiety Disorders in Inhibited Preschool Children. J Consult Clin Psychol. 2005;73:488-497. 
52. Rapee RM, Kennedy SJ, Ingram M, Edwards SL, Sweeney L. Altering the trajectory of anxiety in at-risk young children. $\mathrm{Am}$ J Psychiatry. 2010;167:1518-1525.

53. Kazdin AE. Evidence-based treatment and practice: new opportunities to bridge clinical research and practice, enhance the knowledge base, and improve patient care. Am Psychologist. 2008;63:146-159.

54. Wonders LL. Play therapy for children with selective mutism. In: Kaduson HG, Cangelosi D, Schaefer CE, editors. Prescriptive Play Therapy: Tailoring Interventions for Specific Childhood Problems. New York: Guilford Press; 2020:92-104.

55. Steinhausen HC, Juzi C. Elective mutism: an analysis of 100 cases. J Am Acad Child Adolesc Psychiatry. 1996;35:606-614.

56. Kristensen H. Developmental disorder/delay, anxiety disorder, and elimination disorder. $J \mathrm{Am}$ Acad Child Adolesc Psychiatry. 2000;39:249-256.

57. Manassis K, Tannock R, Garland EJ, Minde K, McInnes A, Clark S. The sounds of silence: language, cognition, and anxiety in selective mutism. J Am Acad Child Adolesc Psychiatry. 2007;46:1187-1195.

58. Cohan SL, Chavira DA, Shipon-Blum E, Hitchcock C, Roesch SC, Stein MB. Refining the classification of children with selective mutism: a latent profile analysis. $J$ Clin Child Adolesc Psychol. 2008;37:770-784.

59. Dow SP, Sonies BC, Scheib D, Moss SE, Leonard HL. Practical guidelines for the assessment and treatment of selective mutism. J Am Acad Child Adolesc Psychiatry. 1995;34:836-846.

60. Dunn LM, Dunn DM. Peabody Picture Vocabulary Test (4th Edition). Minneapolis, MN: Pearson Assessments; 2007.

61. Klein ER, Armstrong SL, Shipon-Blum E. Assessing spoken language competence in children with selective mutism: using parents as test presenters. Commun Disord Q. 2012;34:184-185.

62. Steffenburg H, Steffenburg S, Gillberg C, Billstedt E. Autism spectrum disorder in children with selective mutism. Neuropsychiatr Dis Treat. 2018;14:1163-1169.

63. Klein ER, Ruiz CE, Morales K, Stanley P. Variations in parent and teacher ratings of internalizing, externalizing, adaptive skills, and behavioral symptoms in children with selective mutism. Int $J$ Env Res Public Health. 2019;16:4070.

64. Reynolds C, Kamphaus R. The Behavior Assessment System for Children. 3rd ed. Minneapolis, MN: Pearson Assessments; 2015.
65. Nowakowski ME, Tasker SL, Cunningham CE, et al. Joint attention in parent-child dyads involving children with selective mutism. Child Psychiatry Hum Dev. 2011;42:78-92.

66. Stein MB, Yang BZ, Chavira DA, et al. A common genetic variant in the neurexin superfamily member CNTNAP2 is associated with increased risk for selective mutism and social anxiety traits. Biol Psychiatry. 2011;69:825-831.

67. Muris P, Ollendick TH. Selective mutism and its relations to social anxiety disorder and autism spectrum disorder. Clin Child Fam Psychol Rev. 2021:1-35.

68. Volkmar F, Siegel M, Woodbury-Smith M, King B, McCracken J, State M. Practice parameters for the assessment and treatment of children and adolescents with autism spectrum disorder. J Am Acad Child Adolesc Psychiatry. 2014;53:237-257.

69. Rutter M, Bailey A, Lord C. Social Communication Questionnaire (SCQ). Los Angeles, CA: Western Psychological Services; 2003.

70. Lord C, Rutter M, DiLavore PS, Risi S. Autism Diagnostic Observation Schedule (ADOS). Los Angeles, CA: Western Psychological Services; 1999.

71. Lord C, Rutter M, Le Couteur A. Autism Diagnostic Interview-Revised (ADI-R): a revised version of a diagnostic interview for caregivers of individuals with possible pervasive developmental disorders. J Autism Dev Disord. 1994;24:659-685.

72. Chalfant AM, Rapee RM, Carroll L. Treating anxiety disorders in children with high-functioning autism spectrum disorders: a controlled trial. J Autism Dev Disord. 2007;37:1842-1857.

73. Pallathra AA, Calkins ME, Parish-Morris J, et al. Defining behavioral components of social functioning in adults with autism spectrum disorder as targets for treatment. Autism Res. 2018;11:488-502.

74. Cohan SL, Price JM, Stein MB. Suffering in silence: why a developmental psychopathology perspective in selective mutism is needed. J Dev Behav Pediatr. 2006;27:341-355.

75. Muris P, Ollendick TH. Children who are anxious in silence: a review on selective mutism, the new anxiety disorder in DSM-5. Clin Child Fam Psychol Rev. 2015;18:151-169.
Psychology Research and Behavior Management

\section{Publish your work in this journal}

Psychology Research and Behavior Management is an international, peer-reviewed, open access journal focusing on the science of psychology and its application in behavior management to develop improved outcomes in the clinical, educational, sports and business arenas. Specific topics covered in the journal include: Neuroscience, memory and decision making; Behavior modification and management; Clinica applications; Business and sports performance management; Social and developmental studies; Animal studies. The manuscript management system is completely online and includes a very quick and fair peer-review system, which is all easy to use. Visit http://www. dovepress.com/testimonials.php to read real quotes from published authors. 